\title{
Psicoeducação em Oncologia Pediátrica: Avaliação de um Álbum Seriado no Contexto da Sala de Espera de Exames Invasivos
}

\author{
Azevedo, Priscilla Caroliny Reis de; Maia, Anice Holanda Nunes; Damasceno, Brenna Paula;
} Shioga, Júlia Evangelista Mota; Lima, Maria Juliana Vieira; Gomes, Rebeca Carolinne Castro

Universidade Federal do Ceará - priscilla_caroliny@hotmail.com

Introdução: na Sala de Espera de Procedimentos Invasivos de um centro de tratamento do câncer infanto-juvenil, as intervenções psicológicas têm o objetivo de prestar assistência a pacientes que serão submetidos a exames invasivos, tais como: Biópsia Óssea, Mielograma e Punção Lombar; assim como aos seus acompanhantes. em sua maioria, a díade apresenta sinais claros de ansiedade e medo devido às situações que permeiam a realização e o resultado dos procedimentos. Tal fato se deve, em parte, pelo desconhecimento sobre o que se passa no centro cirúrgico. Assim, a realização dos exames é carregada de fantasias e medos que geram grande ansiedade e dificultam a realização dos procedimentos. por esses motivos, decidiu-se construir um álbum seriado lúdico que mostra diretamente, por meio de fotografias reais editadas, todo o ambiente do centro cirúrgico e as características particulares de cada exame. Dessa maneira, as díades têm a oportunidade de abandonar as explicações mágicas e egocêntricas e pode compreender a doença de uma forma mais lógica. Objetivos: Identificar dados sócio demográficos e assistenciais dos sujeitos envolvidos; verificar e comparar o conhecimento dos sujeitos da pesquisa acerca dos exames, bem como conhecer/analisar o estado emocional desses frente aos exames, antes e depois da apresentação do álbum seriado. Metodologia: Trata-se de um estudo exploratório, descritivo e prospectivo, com metodologia qualitativa. o estudo teve início em Julho 2013 com previsão de término em Junho 2014. a coleta de dados foi realizada de 01 de setembro a 30 de novembro de 2013, tendo como públicoalvo pacientes, a partir de sete anos de idade, de ambos os sexos, em fase diagnóstica ou em tratamento do câncer e acompanhantes acima de 18 anos que consentiram livre e esclarecidamente com tal colaboração. Resultados: Foram coletados 45 protocolos, durante o período citado, e verificou-se em relação aos dados sociodemográficos que $86 \%$ dos pacientes eram adolescentes, $72 \%$ com ensino fundamental incompleto e $86 \%$ estavam realizando o exame para controle da doença, ou seja, já o tinham realizado mais de uma vez. no que se refere aos acompanhantes, $87 \%$ eram mães e adultas, e 35\% tinham ensino médio completo, além disso, constatou-se que em $52 \%$ dessa população, o paciente já havia realizado o exame anteriormente. a análise qualitativa encontra-se em andamento. Conclusões: Considera-se, através dos dados iniciais, que o álbum se mostrou como um importante recurso de mediação entre a equipe de Psicologia e os pacientes, e configurou-se como um instrumento para a realização de intervenções psicoeducativas que podem ajudar no conhecimento sobre a doença, no ajustamento emocional, na criação de estratégias de enfrentamento, na colaboração e adesão ao tratamento e, principalmente, na melhoria da qualidade de vida do paciente, que se sente mais autônomo, implicado e participante desse processo.

Azevedo, Priscilla Caroliny Reis de; Maia, Anice Holanda Nunes; Damasceno, Brenna Paula; Shioga, Júlia Evangelista Mota; Lima, Maria Juliana Vieira; Gomes, Rebeca Carolinne Castro. Psicoeducação em Oncologia Pediátrica: Avaliação de um Álbum Seriado no Contexto da Sala de Espera de Exames Invasivos.. In: Anais do Congresso Internacional de Humanidades \& Humanização em Saúde [= Blucher Medical Proceedings, num.2, vol.1]. São Paulo: Editora Blucher, 2014. ISSN 2357-7282

DOI 10.5151/medpro-cihhs-10773 